\title{
Management of recurrent intracranial aneurysms after coil embolization: a novel classification scheme based on angiography
}

\author{
Le-Bao Yu, MD, ${ }^{1}$ Xin-Jian Yang, MD, ${ }^{2}$ Qian Zhang, MD, ${ }^{1}$ Shao-Sen Zhang, MM, ${ }^{1}$ Yan Zhang, MD, ${ }^{1}$ \\ Rong Wang, MD, ${ }^{1}$ and Dong Zhang, MD1
}

\begin{abstract}
1Department of Neurosurgery, Beijing Tiantan Hospital, Capital Medical University; China National Clinical Research Center for Neurological Diseases; Center of Stroke, Beijing Institute for Brain Disorders; and Beijing Key Laboratory of Translational Medicine for Cerebrovascular Disease, Beijing; and ²Department of Interventional Neuroradiology, Beijing Neurosurgical Institute and Beijing Tiantan Hospital, Capital Medical University, Beijing, China
\end{abstract}

OBJECTIVE Recurrent aneurysms after coil embolization remain a challenging issue. The goal of the present study was to report the authors' experience with recurrent aneurysms after coil embolization and to discuss the radiographic classification scheme and recommended management strategy.

METHODS Aneurysm treatments from a single institution over a 6-year period were retrospectively reviewed. Ninetyseven aneurysms that recurred after initial coiling were managed during the study period. Recurrent aneurysms were classified into the following 5 types based on their angiographic characteristics: I, pure recanalization inside the aneurysm sac; II, pure coil compaction without aneurysm growth; III, new aneurysm neck formed without coil compaction; IV, new aneurysm neck formed with coil compaction; and V, newly formed aneurysm neck and sac.

RESULTS Aneurysm recurrences resulted in rehemorrhages in 6 cases (6.2\%) of type III-V aneurysms, but in none of type I-II aneurysms. There was a significantly higher proportion of ophthalmic artery aneurysms and complex internal carotid artery aneurysms presenting as types I and II than presented as the other 3 types $(63.3 \%$ vs $16.4 \%, p<0.001)$. In contrast, for posterior communicating artery aneurysms and anterior communicating artery aneurysms, a higher proportion of type III-V aneurysms was observed than for the other 2 types, but without a significant difference in the multivariate model ( $56.7 \%$ vs $23.3 \%)$. In addition, giant (> $25 \mathrm{~mm}$ ) aneurysms were more common among type I and II lesions than among type III and IV aneurysms (36.7\% vs $9.0 \%, p=0.001)$, which exhibited a higher proportion of small $(<10 \mathrm{~mm}$ ) lesions $(65.7 \%$ vs $13.3 \%, p<0.001)$. A single reembolization procedure was sufficient to occlude $80.0 \%$ of type I recurrences and $83.3 \%$ of type II recurrences from coil compaction but only $65.6 \%$ of type III-V recurrences from aneurysm regrowth.

CONCLUSIONS Aneurysm size and location represent the determining factors of the angiographic recurrence types. Type I and II recurrences were safely treated by reembolization, whereas type III-V recurrences may be best managed surgically when technically feasible.

https://thejns.org/doi/abs/10.3171/2018.6.JNS181046

KEYWORDS recurrent aneurysm; coiling; retreatment; clipping; classification; vascular disorders

$\mathrm{E}$ NDOVASCULAR treatment has proven to be effective in the management of intracranial aneurysm, and can achieve permanent occlusion in up to $85 \%$ of cases, reducing the bleeding or rebleeding rate. ${ }^{6,10,14}$ Thus, a paradigm shift from microsurgical clipping to endovascular intervention has been observed since the publication of the International Subarachnoid Aneurysm Trial. ${ }^{11,13}$ However, the expansion of endovascular therapy has led to a significant increase in documented incidences of incomplete aneurysm obliteration, neck remnants, and recurrences, indicating an association between endovascular treatment and aneurysm rerupture in the current literature..$^{2-4,712}$

Aneurysm recurrence after coil embolization remains both a major shortcoming of endovascular treatment and

ABBREVIATIONS ACOA = anterior communicating artery; ICA = internal carotid artery; OphA = ophthalmic artery; PCoA = posterior communicating artery. SUBMITTED April 17, 2018. ACCEPTED June 28, 2018.

INCLUDE WHEN CITING Published online November 23, 2018; DOI: 10.3171/2018.6.JNS181046. 
a daunting challenge for neurosurgeons without optimal management strategies. ${ }^{1,3,5,21}$ However, few data are available regarding the morphological changes of recurrent aneurysms and their management strategy. The modified Raymond scale or the original Raymond scale ${ }^{8,15-17,19}$ is a well-known classification system for initial angiographic results of endovascular treatment, although it was not sufficient to describe all morphological changes of aneurysm recurrence over time. Other classifications ${ }^{5,18,20,22}$ described the morphological changes of aneurysm recurrence involving coil compaction, aneurysm regrowth, and fundal migration, but no systematic classification for recurrent aneurysms has been established. Thus, in the current study, we describe our experience spanning more than 7 years at a single center with 97 aneurysms that recurred after coil embolization, and we propose a novel classification scheme through angiographic analysis of the characteristics of recurrent aneurysms. Furthermore, the type-specific management recommendations based on the analysis of the outcomes of recurrent aneurysms of different types were provided.

\section{Methods \\ Patient Population}

The study was approved by the Ethics Committee of our medical center. As the biggest neurosurgical center in China, our institution provided treatment for a huge volume of aneurysms. During the 6-year period from 2011 to 2017, a total of 6008 patients were treated for intracranial aneurysm at the Department of Neurosurgery in our hospital. Aneurysm obliteration was routinely recorded after initial coiling. Follow-up diagnosis of aneurysms in patients who underwent endovascular coiling was based on images obtained using digital subtraction angiography or 3D CT angiography at least once within 6 months to 1 year of initial coiling. During the study period, we identified 97 patients with recurrent aneurysms after initial coil embolization involving aneurysms initially treated in other institutions. Aneurysm residues were defined as coiled aneurysms with subtotal obliteration or persistent aneurysm filling immediately after initial coiling, and were classified according to Raymond et al. as complete (grade 1), residual neck (grade 2), and residual aneurysms (grade 3). Recurrent aneurysms were defined as coiled aneurysms with a recurring or larger persistent filling defect on angiography studies obtained during later follow-up than the defect that occurred after initial treatment and follow-up. Remnants that either did not regrow or become ruptured were excluded.

\section{Classification of Recurrence}

We classified recurrent aneurysms after coil embolization into 5 different types based only on their imaging characteristics on digital subtraction angiography. Coil compaction and aneurysm regrowth were the main mechanisms of aneurysm recurrence after endovascular treatment, as is shown in this article.

Recurrence types are defined as follows. Type I: recurrent aneurysm exhibiting pure recanalization inside the packed coils, presenting scattered, small, dot-like filling inside the aneurysm sac on angiographic imaging. This type of aneurysm was mainly caused by loose packing, coil compaction, or a hemodynamic mechanism. Type II: recurrent aneurysm exhibiting pure coil compaction in the aneurysm neck and sac, thus presenting aneurysm neck and sac filling without aneurysmal growth. In this type of recurrent aneurysm, coils inside the aneurysm were notably compacted toward the aneurysm fundus. Type III: a new aneurysm neck formed without significant coil compaction in the initial aneurysm neck and sac. Type IV: a new aneurysm neck formed with significant coil compaction in the initial aneurysm neck and sac. The newly formed aneurysm neck in type III and type IV aneurysms was generally regular without outgrowth of new aneurysm sacs. Type V: a new aneurysm sac originated from the initial aneurysm neck, usually with irregular shape, together with or without coil compaction in the initial aneurysm sac (Fig. 1).

\section{Treatment and Follow-Up}

In our medical center, we attempted to treat recurrent aneurysms after initial coiling by additional endovascular treatment whenever technically feasible. Aneurysms that could not be addressed by endovascular treatment or patients who rejected the endovascular treatment underwent microsurgical clipping. The Glasgow Outcome Scale was used to document the patients' functional status on followup; scores of 4-5 were considered favorable outcomes.

\section{Statistical Methods}

Categorical data were analyzed using the chi-square test or Fisher's exact test. Continuous data were analyzed using the Student t-test or 1-way ANOVA with the multiple comparison post hoc test. We performed multivariate analyses to identify risk factors associated with recurrence type. For all statistical analyses, $\mathrm{p}<0.05$ was considered statistically significant.

\section{Results}

\section{Patient Presentation and Aneurysm Characteristics}

Over the 6-year study period, 97 patients experienced relevant aneurysm recurrences and required additional treatment. Patient and aneurysm characteristics are summarized in Table 1 according to the novel classification scheme. The most common type of recurrent aneurysm was type $\mathrm{V}(\mathrm{n}=35 ; 36.1 \%)$, followed by type II $(\mathrm{n}=20$; $20.6 \%)$, type III ( $\mathrm{n}=16 ; 16.5 \%)$, type IV $(\mathrm{n}=16 ; 16.5 \%)$, and type $\mathrm{I}(\mathrm{n}=10 ; 10.3 \%)$. The patients ranged in age from 16 to 76 years $(47.4 \pm 11.5$ years, mean $\pm S D)$, and the female/male ratio was 1.7:1 without significant differences among different aneurysm types. Fifty-nine patients $(60.8 \%)$ underwent endovascular treatment for ruptured aneurysms with no significant difference among different aneurysm types. However, aneurysm recurrences resulted in rehemorrhages in 6 cases (6.2\%), including 4 cases of type V, 1 case of type IV, and 1 case of type III aneurysm. All 3 types were recurrent aneurysms with aneurysmal growth or a newly formed aneurysm sac.

A correlation was found among the recurrence type, aneurysm size, aneurysm location, and the immediate angiographic outcome of aneurysmal residue after initial 

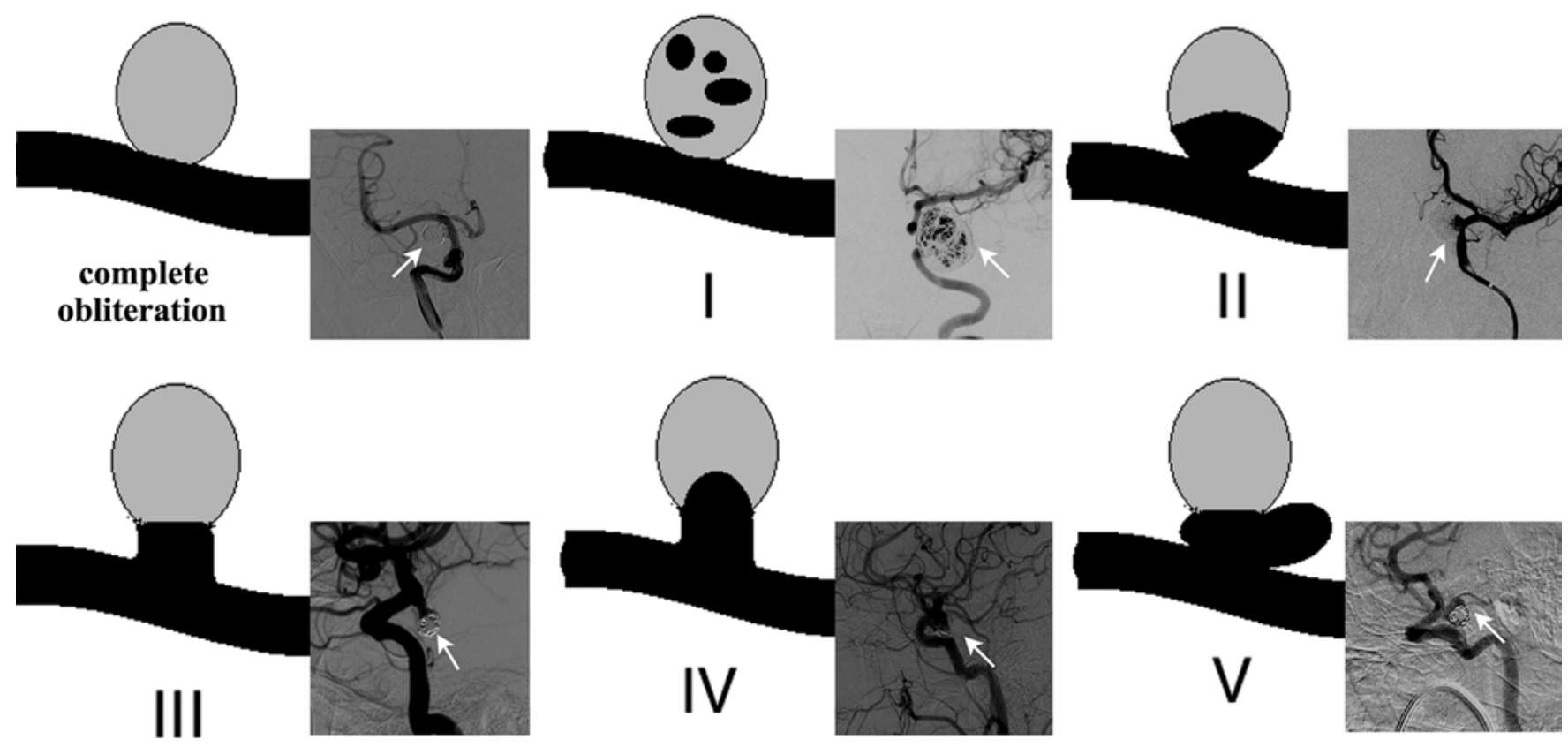

FIG. 1. Drawings and angiographic images showing the different types of recurrent aneurysms (arrows). Gray represents the coiled aneurysm, and black represents contrast agent filling. Type I: recurrent aneurysm exhibiting pure recanalization inside the packed coils, presenting scattered, small, dot-like filling inside the aneurysm sac on angiographic imaging. Type Il: recurrent aneurysm exhibiting pure coil compaction in the aneurysm neck and sac, presenting aneurysm neck and sac filling without aneurysmal growth. Type III: a new aneurysm neck formed without significant coil compaction in the initial aneurysm neck and sac. Type IV: a new aneurysm neck formed with significant coil compaction in the initial aneurysm neck and sac. Type V: a new aneurysm sac originated from the initial aneurysm neck, usually with an irregular shape, with or without coil compaction in the initial aneurysm sac.

treatment (Raymond scale). In detail, only one type of aneurysmal residue was observed after the initial treatment in certain types of recurrent aneurysms; for example, aneurysmal residue of Raymond class III was only observed in type I recurrent aneurysms (Table 1), although without significant difference $(\mathrm{p}=0.244)$. There was a significantly higher proportion of ophthalmic artery (OphA) aneurysms and aneurysms located in the bifurcation, cavernous segment, or petrous segment of the internal carotid artery (ICA) that presented as type I and type II lesions than in those that presented as the other 3 types of aneurysm (hazard ratio [HR] 0.100, 95\% CI 0.014-0.711, p = 0.021 for types I and II; HR $0.084,95 \%$ CI $0.009-0.754$, p $=0.027$ for types III-V). However, for posterior communicating artery (PCoA) and anterior communicating artery (ACoA) aneurysms, a significantly higher proportion $(38 / 67,56.7 \%)$ of type III-V aneurysms was observed but without significant difference in the multivariate model. In addition, posterior circulation aneurysms of type IV and $\mathrm{V}$ were more common $(12 / 51,23.5 \%)$. Giant $(>25 \mathrm{~mm})$ aneurysms were more common among type I-II than among type III-IV lesions, which exhibited a higher proportion of small $(<10 \mathrm{~mm}$ ) aneurysms (HR 8.636, 95\% CI $1.276-58.465 ; \mathrm{p}=0.027$ ) (Table 2). The mean posttreatment interval was 25.6 months (range 1-167 months) for all recurrent aneurysms, with no significant difference among the aneurysm types $(\mathrm{p}=0.630)$.

\section{Management and Outcomes}

Management methods and outcomes are summarized in Table 3 according to the novel classification scheme. Endovascular interventions including standard coil embolization or stent-protected coiling were performed in $72(74.2 \%)$ patients. Microsurgical clipping was successfully performed in $25(25.8 \%)$ patients without requiring complex revascularization. Incomplete obliteration after retreatment was observed in $23(23.7 \%)$ recurrent aneurysms after recoiling, among which type I aneurysm was most common (77.8\%). Surgery-related cerebral infarction occurred in type IV and type V aneurysms after coiling and clipping. Of 97 patients, $90(92.8 \%)$ were clinically followed by telephone, and $66(68.0 \%)$ were angiographically followed. The mean follow-up duration for those two groups was $38.0 \pm 5.3$ months and $16.8 \pm 5.3$ months, respectively (mean $\pm \mathrm{SD}$ ). Favorable outcomes were achieved in $82.2 \%$ patients, without a significant difference among aneurysm types. Repeated recurrence was observed in all types of aneurysms after retreatment with coil embolization. However, the recurrence rate of type I aneurysm was unexpectedly low $(1 / 5,20 \%)$. A single reembolization was sufficient to occlude $80.0 \%$ of type I recurrences and $83.3 \%$ of type II recurrences (from coil compaction) but only $65.6 \%$ of type III-V recurrences (from aneurysm regrowth). A single operation using microsurgical clipping was sufficient to occlude $100 \%$ of all types of recurrence according to the results of the current study.

\section{Discussion}

The classification of angiographic results and the diagnosis of a recurrent aneurysm are subjective evaluations 
TABLE 1. Baseline demographic and clinical characteristics of the recurrent aneurysms

\begin{tabular}{|c|c|c|c|c|c|}
\hline \multirow[b]{2}{*}{ Characteristic } & \multicolumn{5}{|c|}{ Recurrence Types } \\
\hline & $\mathrm{I}, \mathrm{n}=10$ & II, $n=20$ & $\mathrm{III}, \mathrm{n}=16$ & $\mathrm{IV}, \mathrm{n}=16$ & $V, n=35$ \\
\hline Age, median (range, yrs) & $51.5(36-71)$ & $52.5(25-63)$ & $45(16-66)$ & $51(35-65)$ & $47(18-76)$ \\
\hline Female & $8(80.0)$ & $16(80.0)$ & $10(62.5)$ & $10(62.5)$ & $17(48.6)$ \\
\hline Initial rupture & $1(10.0)$ & $9(45.0)$ & $16(100.0)$ & $11(68.8)$ & $22(62.9)$ \\
\hline \multicolumn{6}{|c|}{ Outcome after initial Tx, Raymond scale } \\
\hline Grade 1 & $2(20.0)$ & $13(65.0)$ & $14(87.5)$ & $12(75.0)$ & $29(82.9)$ \\
\hline Grade 2 & $0(0.0)$ & $7(35.0)$ & $2(12.5)$ & $2(12.5)$ & $6(17.1)$ \\
\hline Grade 3 & $8(80.0)$ & $0(0.0)$ & $0(0.0)$ & $2(12.5)$ & $0(0.0)$ \\
\hline Rupture on presentation & $0(0.0)$ & $0(0.0)$ & $1(6.3)$ & $1(6.3)$ & $4(11.4)$ \\
\hline \multicolumn{6}{|l|}{ Aneurysm location } \\
\hline PCoA & $0(0.0)$ & $5(25.0)$ & $9(56.3)$ & $6(37.5)$ & $5(14.3)$ \\
\hline $\mathrm{ACOA}$ & $1(10.0)$ & $1(5.0)$ & $4(25.0)$ & $4(25.0)$ & $10(28.6)$ \\
\hline OphA & $5(50.0)$ & $5(25.0)$ & $3(18.7)$ & $1(6.3)$ & $3(8.6)$ \\
\hline $\mathrm{ICA}^{*}$ & $4(40.0)$ & $5(25.0)$ & $0(0.0)$ & $0(0.0)$ & $4(11.4)$ \\
\hline MCA & $0(0.0)$ & $1(5.0)$ & $0(0.0)$ & $1(6.3)$ & $3(8.6)$ \\
\hline ACA & $0(0.0)$ & $1(5.0)$ & $0(0.0)$ & $1(6.3)$ & $1(2.9)$ \\
\hline Posterior circulation $†$ & $0(0.0)$ & $2(10.0)$ & $0(0.0)$ & $3(18.7)$ & $9(25.7)$ \\
\hline \multicolumn{6}{|l|}{ Aneurysm size } \\
\hline$<10 \mathrm{~mm}$ & $1(10.0)$ & $3(15.0)$ & $14(87.5)$ & $9(56.3)$ & $21(60.0)$ \\
\hline $10-25 \mathrm{~mm}$ & $2(20.0)$ & $13(65.0)$ & $2(12.5)$ & $7(43.7)$ & $8(22.9)$ \\
\hline$>25 \mathrm{~mm}$ & $7(70.0)$ & $4(20.0)$ & $0(0.0)$ & $0(0.0)$ & $6(17.1)$ \\
\hline
\end{tabular}

that may differ from one center to another. ${ }^{3,5,9,18,20}$ Raymond and colleagues ${ }^{15,16,19}$ proposed a classification system for immediate angiographic results of endovascular treatment, but their scale did not clearly classify recurrences, and chose to distinguish "minor" from "major" recurrences. An aneurysm was classified as a "major" recurrence if it was saccular and if its size would theoretically permit retreatment with coils. Roy et al. ${ }^{19}$ explained that their definition of recurrence might not reveal all morphological changes over time, and their goal was to assess how often patients had unsatisfactory angiographic results (grade 3) immediately after treatment and how often grade 1 and 2 results had an evolution toward grade 3 during follow-up.

Dorfer et al. ${ }^{5}$ described the mechanisms of aneurysm recurrence after endovascular treatment as the following 3 types: coil compaction (a), aneurysm regrowth (b), and fundal migration (c). The type $\mathrm{c}$ aneurysm described by the authors was difficult to assess in endovascular treatment; type c aneurysms could be assessed only by direct surgery, because a clear differentiation between regrowth and coil translocation out of the aneurysm sac-both of which manifest as increased fundus height via angiography-is only possible during surgery. The authors also found that recurrences from coil compaction were safely treated by recoiling, whereas recurrences from aneurysm regrowth might be best managed surgically because a single reembolization was sufficient to occlude in $78.7 \%$ of recurrences from coil compaction, but in only $14.3 \%$ of recurrences from aneurysm regrowth.

Waldron et al. ${ }^{22}$ documented a high rate of coil extrusion (55\% in recurrent aneurysms) in their study and concluded that coil extrusion occurs more often than expected and is often misdiagnosed on angiography as simply compaction. Three mechanisms of aneurysm recurrence were described in their study, including coil compaction, recanalization, and coil extrusion. The authors recommended direct clipping for coiled aneurysms; the need for this procedure might be predicted by the relationship between coil width and compaction height $(\mathrm{C} / \mathrm{H}<2.5$, or a wedge angle $\left.<90^{\circ}\right)$. Therefore, few data are available regarding the systematic classification of recurrent aneurysms and their management strategy. In the current study, we proposed a novel classification scheme for recurrent aneurysms based only on angiographic findings, which might be more systematic and specific for the detection of recurrences.

We performed a detailed analysis of the characteristics of the 5 types of aneurysms. The results of our current study demonstrated a correlation among the classification of aneurysmal residue after initial treatment, rehemorrhages, aneurysm size, aneurysm location, and recurrence type. In particular, aneurysm growth was a risk factor for rehemorrhage in recurrent aneurysm; rehemorrhage occurred only in type III-V aneurysms (lesions with aneurysmal growth or a newly formed aneurysm sac). Re- 


\begin{tabular}{|c|c|c|c|c|c|c|}
\hline \multirow[b]{2}{*}{ Risk Factor } & \multicolumn{2}{|c|}{ Recurrence Type } & \multirow[b]{2}{*}{ Chi-Square Test } & \multirow[b]{2}{*}{ p Value } & \multirow[b]{2}{*}{ Multivariate Analysis, HR $(95 \% \mathrm{Cl})$} & \multirow[b]{2}{*}{$\mathrm{p}$ Value } \\
\hline & $I-I I, n=30$ & $I I I-V, n=67$ & & & & \\
\hline Outcome after initial Tx, Raymond scale & & & 7.532 & 0.001 & - & 0.244 \\
\hline Grade 1 & $15(50.0)$ & $55(82.1)$ & 10.623 & 0.001 & $4.348(0.767-24.642)$ & 0.097 \\
\hline Grade 2 & $7(23.3)$ & $10(14.9)$ & 1.013 & 0.314 & $2.789(0.404-19.258)$ & 0.298 \\
\hline Grade 3 & $8(26.7)$ & $2(3.0)$ & 10.137 & 0.001 & Reference & - \\
\hline Aneurysm location & & & 3.786 & 0.001 & - & 0.031 \\
\hline PCoA & $5(16.7)$ & $20(29.9)$ & 1.883 & 0.170 & $0.221(0.029-1.696)$ & 0.147 \\
\hline $\mathrm{ACoA}$ & $2(6.7)$ & $18(26.9)$ & 5.165 & 0.023 & $0.283(0.026-3.117)$ & 0.303 \\
\hline OphA & $10(33.3)$ & $7(10.4)$ & 7.508 & 0.006 & $0.100(0.014-0.711)$ & 0.021 \\
\hline$I A^{*}$ & $9(30.0)$ & $4(6.0)$ & 8.343 & 0.04 & $0.084(0.009-0.754)$ & 0.027 \\
\hline MCA & $1(3.3)$ & $4(6.0)$ & - & $0.507 \ddagger$ & $0.122(0.006-2.562)$ & 0.175 \\
\hline ACA & $1(3.3)$ & $2(3.0)$ & - & $0.675 \ddagger$ & $0.075(0.003-1.996)$ & 0.122 \\
\hline Posterior circulation $†$ & $2(6.7)$ & $12(17.9)$ & 1.308 & 0.145 & Reference & - \\
\hline Aneurysm size & & & 12.180 & $<0.001$ & - & 0.011 \\
\hline$<10 \mathrm{~mm}$ & $4(13.3)$ & $44(65.7)$ & 22.708 & $<0.001$ & $8.636(1.276-58.465)$ & 0.027 \\
\hline $10-25 \mathrm{~mm}$ & $15(50.0)$ & $17(25.4)$ & 5.685 & 0.017 & $1.022(0.206-5.067)$ & 0.978 \\
\hline$>25 \mathrm{~mm}$ & $11(36.7)$ & $6(9.0)$ & 11.009 & 0.001 & Reference & - \\
\hline
\end{tabular}

- = not applicable.

Unless otherwise indicated, values are expressed as the number of patients (\%).

* Location of aneurysm originating from the ICA involved the bifurcation, cavernous segment, and petrous segment.

$\dagger$ Location of aneurysm originating from the posterior circulation involved posterior cerebral artery, basilar artery, and vertebral artery.

$\ddagger$ Fisher's exact test was used.

hemorrhage did not occur in type I-II aneurysms. Aneurysmal residue after initial coiling was correlated with an increased risk of aneurysm recurrence. Furthermore, the type of aneurysmal residue might determine the type of aneurysm recurrence; our results showed that only one type of aneurysmal residue was observed in a certain type of recurrent aneurysm. In addition, giant aneurysms located in the OphA or certain segments of the ICA (the bifurcation, cavernous segment, or petrous segment) were more likely to result in type I-II aneurysm recurrence, whereas small aneurysms located in the PCoA or ACoA were more likely to result in type III-V aneurysm recurrence. Recurrent aneurysms of types IV and V were more common than those of other types in the posterior circulation. These findings imply that some specificity may exist in the etiologies of different types of recurrences.

To propose some treatment recommendations for patients with recurrent aneurysm after endovascular coiling, we also performed a detailed comparative analysis of the outcomes of the 5 types of aneurysms following coiling or

TABLE 3. Outcomes of recurrent aneurysm with different types after second treatment

\begin{tabular}{|c|c|c|c|c|c|c|c|c|c|c|}
\hline \multirow[b]{3}{*}{ Outcome } & \multicolumn{10}{|c|}{ Recurrence Type \& Tx Method } \\
\hline & \multicolumn{2}{|c|}{$I, n=10$} & \multicolumn{2}{|c|}{$I I, n=20$} & \multicolumn{2}{|c|}{ III, $n=16$} & \multicolumn{2}{|c|}{$I V, n=16$} & \multicolumn{2}{|c|}{$V, n=35$} \\
\hline & $\begin{array}{c}\text { Recoiling, } \\
n=9\end{array}$ & $\begin{array}{c}\text { Clipping, } \\
n=1\end{array}$ & $\begin{array}{c}\text { Recoiling, } \\
n=17\end{array}$ & $\begin{array}{c}\text { Clipping, } \\
n=3\end{array}$ & $\begin{array}{c}\text { Recoiling, } \\
n=11\end{array}$ & $\begin{array}{c}\text { Clipping, } \\
n=5\end{array}$ & $\begin{array}{l}\text { Recoiling, } \\
n=11\end{array}$ & $\begin{array}{c}\text { Clipping, } \\
n=5\end{array}$ & $\begin{array}{l}\text { Recoiling, } \\
n=24\end{array}$ & $\begin{array}{c}\text { Clipping, } \\
n=11\end{array}$ \\
\hline $\begin{array}{l}\text { Residue after re- } \\
\text { Tx, no. (\%) }\end{array}$ & $7(77.8)$ & $0(0.0)$ & $2(11.8)$ & $0(0.0)$ & $2(18.2)$ & $0(0.0)$ & $2(18.2)$ & $0(0.0)$ & $5(20.8)$ & $0(0.0)$ \\
\hline $\begin{array}{l}\text { Op-related cere- } \\
\text { bral infarction, } \\
\text { no. }(\%)\end{array}$ & $0(0.0)$ & $0(0.0)$ & $0(0.0)$ & $0(0.0)$ & $0(0.0)$ & $0(0.0)$ & $0(0.0)$ & $1(20.0)$ & $1(4.2)$ & $2(18.2)$ \\
\hline $\begin{array}{l}\text { Favorable out- } \\
\text { come at FU* }\end{array}$ & $7 / 8(87.5)$ & $1 / 1(100.0)$ & $15 / 17(88.2)$ & $2 / 3(66.7)$ & $5 / 7(71.5)$ & $4 / 5(80.0)$ & $10 / 11(90.9)$ & $4 / 5(80.0)$ & $18 / 22(81.8)$ & $8 / 11(72.7)$ \\
\hline Recurrence $†$ & $1 / 5(20.0)$ & $0 / 0(0.0)$ & $2 / 12(16.7)$ & $0 / 2(0.0)$ & $3 / 8(37.5)$ & $0 / 4(0.0)$ & $3 / 9(33.3)$ & $0 / 4(0.0)$ & $5 / 15(33.3)$ & $0 / 7(0.0)$ \\
\hline
\end{tabular}

$\mathrm{FU}=$ follow-up.

* Values are expressed as number of patients with favorable outcome/number of successfully followed patients (\%). Favorable outcome is designated as Glasgow

Outcome Scale score 4-5.

† Values are expressed as number of patients with aneurysm recurrence/number of patients with radiographic follow-up (\%). 
clipping. Although the incomplete obliteration rate after coiling retreatment was significantly higher than that after surgical clipping ( $23.7 \%$ vs $0 \%)$, especially for type I aneurysm (77.8\%), $80.0 \%$ of type I recurrences and $83.3 \%$ of type II recurrences were completely occluded, followed by $65.6 \%$ of type III-V recurrences. In addition, although $100 \%$ of all types of recurrences were completely occluded after direct surgery in the current study, there was a small number of small aneurysms treated by clipping in the type I and II aneurysm group. Direct clipping of large and giant recurrent aneurysms, especially type I and II lesions, would be very challenging, with high morbidity, and would therefore not be recommended. Furthermore, favorable outcomes were achieved in $82.2 \%$ of patients, without a significant difference in the type of aneurysms and treatment methods, although a higher morbidity rate of operation-related cerebral infarction occurred in type IV and type $\mathrm{V}$ aneurysms than in the other type of lesions after clipping (18.8\%). Therefore, surgical clipping might be suggested for type III-V aneurysms because a higher complete obliteration rate $(100 \%$ vs $65.6 \%, \mathrm{p}<0.001)$ could be achieved with comparable clinical outcomes $(76.2 \%$ vs $82.5 \%$ with favorable outcomes, $\mathrm{p}=0.556$ ) in comparison with endovascular coiling.

\section{Limitations of the Study}

The current study was a retrospective report on cases treated at a single center. Unfortunately, because only $68.0 \%$ of patients were angiographically followed, the true rate of recurrence is not yet known. In addition, the proportion of recurrent aneurysms that underwent microsurgical clipping was much lower than that of recurrent aneurysms that underwent coiling, which might result in the bias of the outcomes for recurrent aneurysms. Furthermore, validation of the rating scale as it related to future rupture risk was lacking for this study, which could provide a good definition of what is needed in terms of trial design for future studies. Although the appropriateness of our classification needs to be evaluated in future studies with larger groups, we believe that this classification will be accepted by most neurosurgeons. Additional studies are needed to evaluate the effects of management strategies that are developed using our classification on the outcomes of recurrent aneurysm treated using our classification in a broad population.

\section{Conclusions}

In the present report, we have identified different subsets of aneurysm recurrences that are suitable for different treatment strategies. The classification of aneurysmal residue after initial treatment, aneurysm size, and aneurysm location are important parameters for predicting the type of aneurysm recurrence and, thus, for identifying the appropriate treatment methods. According to the novel classification scheme proposed herein, type I and II aneurysms can be safely treated by additional endovascular procedures with acceptable occlusion rates and long-term outcomes. In contrast, type III-V aneurysms have a tendency to repeatedly regenerate and recur, even after additional endovascular procedures, and may be prone to rehemorrhage; therefore, these aneurysms may be best managed surgically when technically feasible.

\section{Acknowledgments}

Funding was received from the China National Clinical Research Center for Neurosurgical Diseases (NCRC-ND) (2015BAI12B04).

\section{References}

1. Boet R, Poon WS, Yu SC: The management of residual and recurrent intracranial aneurysms after previous endovascular or surgical treatment-a report of eighteen cases. Acta Neurochir (Wien) 143:1093-1101, 2001

2. CARAT Investigators: Rates of delayed rebleeding from intracranial aneurysms are low after surgical and endovascular treatment. Stroke 37:1437-1442, 2006

3. Chung J, Lim YC, Kim BS, Lee D, Lee KS, Shin YS: Early and late microsurgical clipping for initially coiled intracranial aneurysms. Neuroradiology 52:1143-1151, 2010

4. Debrun GM, Aletich VA, Thornton J, Alazzaz A, Charbel FT, Ausman JI, et al: Techniques of coiling cerebral aneurysms. Surg Neurol 53:150-156, 2000

5. Dorfer C, Gruber A, Standhardt H, Bavinzski G, Knosp E: Management of residual and recurrent aneurysms after initial endovascular treatment. Neurosurgery 70:537-554, 2012

6. Guglielmi G, Viñuela F, Sepetka I, Macellari V: Electrothrombosis of saccular aneurysms via endovascular approach. Part 1: electrochemical basis, technique, and experimental results. J Neurosurg 75:1-7, 1991

7. Hayakawa M, Murayama Y, Duckwiler GR, Gobin YP, Guglielmi G, Viñuela F: Natural history of the neck remnant of a cerebral aneurysm treated with the Guglielmi detachable coil system. J Neurosurg 93:561-568, 2000

8. Lecler A, Raymond J, Rodriguez-Régent C, Al Shareef F, Trystram D, Godon-Hardy S, et al: Intracranial aneurysms: recurrences more than 10 years after endovascular treatment-a prospective cohort study, systematic review, and meta-analysis. Radiology 277:173-180, 2015

9. Lejeune JP, Thines L, Taschner C, Bourgeois P, Henon H, Leclerc X: Neurosurgical treatment for aneurysm remnants or recurrences after coil occlusion. Neurosurgery 63:684692,2008

10. Lin N, Cahill KS, Frerichs KU, Friedlander RM, Claus EB: Treatment of ruptured and unruptured cerebral aneurysms in the USA: a paradigm shift. J Neurointerv Surg 4:182-189, 2012

11. Molyneux A, Kerr R, Stratton I, Sandercock P, Clarke M, Shrimpton J, et al: International Subarachnoid Aneurysm Trial (ISAT) of neurosurgical clipping versus endovascular coiling in 2143 patients with ruptured intracranial aneurysms: a randomised trial. Lancet 360:1267-1274, 2002

12. Molyneux AJ, Kerr RS, Birks J, Ramzi N, Yarnold J, Sneade M, et al: Risk of recurrent subarachnoid haemorrhage, death, or dependence and standardised mortality ratios after clipping or coiling of an intracranial aneurysm in the International Subarachnoid Aneurysm Trial (ISAT): long-term follow-up. Lancet Neurol 8:427-433, 2009

13. Molyneux AJ, Kerr RS, Yu LM, Clarke M, Sneade M, Yarnold JA, et al: International Subarachnoid Aneurysm Trial (ISAT) of neurosurgical clipping versus endovascular coiling in 2143 patients with ruptured intracranial aneurysms: a randomised comparison of effects on survival, dependency, seizures, rebleeding, subgroups, and aneurysm occlusion. Lancet 366:809-817, 2005

14. Qureshi AI, Vazquez G, Tariq N, Suri MF, Lakshminarayan K, Lanzino G: Impact of International Subarachnoid Aneurysm Trial results on treatment of ruptured intracranial aneurysms in the United States. Clinical article. J Neurosurg 114:834-841, 2011 
15. Raymond J, Guilbert F, Weill A, Georganos SA, Juravsky L, Lambert A, et al: Long-term angiographic recurrences after selective endovascular treatment of aneurysms with detachable coils. Stroke 34:1398-1403, 2003

16. Raymond J, Guilbert F, Weill A, Roy D: Follow-up of treated aneurysms: the challenge of recurrences and potential solutions. Neuroimaging Clin N Am 16:513-523, ix, 2006

17. Raymond J, Roy D: Safety and efficacy of endovascular treatment of acutely ruptured aneurysms. Neurosurgery 41:1235-1246, 1997

18. Romani R, Lehto H, Laakso A, Horcajadas A, Kivisaari R, von und zu Fraunberg M, et al: Microsurgery for previously coiled aneurysms: experience with 81 patients. Neurosurgery 68:140-154, 2011

19. Roy D, Milot G, Raymond J: Endovascular treatment of unruptured aneurysms. Stroke 32:1998-2004, 2001

20. Rubino PA, Mura J, Kitroser M, Bottan JS, Salas E, Lambre $\mathrm{J}$, et al: Microsurgical clipping of previously coiled aneurysms. World Neurosurg 82:e203-e208, 2014

21. Sanai N, Caldwell N, Englot DJ, Lawton MT: Advanced technical skills are required for microsurgical clipping of posterior communicating artery aneurysms in the endovascular era. Neurosurgery 71:285-295, 2012

22. Waldron JS, Halbach VV, Lawton MT: Microsurgical management of incompletely coiled and recurrent aneurysms: trends, techniques, and observations on coil extrusion. Neurosurgery 64 (5 Suppl 2):301-317, 2009

\section{Disclosures}

The authors report no conflict of interest concerning the materi- als or methods used in this study or the findings specified in this paper.

\section{Author Contributions}

Conception and design: D Zhang, Q Zhang. Acquisition of data: Yu, Q Zhang, SS Zhang. Analysis and interpretation of data: Yu, Q Zhang, SS Zhang. Drafting the article: Yu. Critically revising the article: Yang, Y Zhang. Reviewed submitted version of manuscript: D Zhang, Y Zhang, Wang. Approved the final version of the manuscript on behalf of all authors: D Zhang. Statistical analysis: SS Zhang. Administrative/technical/material support: Y Zhang, Wang. Study supervision: D Zhang, Wang.

\section{Supplemental Information}

\section{Online-Only Content}

Supplemental material is available with the online version of the article.

Supplementary Materials. https://thejns.org/doi/suppl/10.3171/ 2018.6.JNS181046.

\section{Correspondence}

Dong Zhang: Beijing Tiantan Hospital, Capital Medical University, Beijing, China. zhangdong0660@aliyun.com. 